fauna, which have developed on these Islands after millions of years of evolution. Deforestation enhances soil erosion and leads to increased input of agrochemicals and domestic wastes, which find their way to near-shore waters, endangering marine biota and also entering the human food-chain. Combustion of petrochemicals in generators and automobiles will pollute the healthy atmosphere of the capital city, Port Blair, by adding more harmful gases and noxious fumes. Nondegradable disposable wastes and insanitation will create health-hazards - through contamination, sedimentation, and pollution.
Consequently there is the most urgent need for family planning, with adoption of appropriate technology that must be suited to local conditions - to conserve and preserve the existing environment - by avoiding or minimizing the foreseeable damage to the ecology of these beautiful islands, prior to its reaching irreparable levels.

T.C. KHATRI
J.N. Government College
Port Blair 744101
Andamans, India.

J.N. Government College Andamans, India.

\title{
Advisory Board on Sustainable Development
}

$\mathrm{T}^{-}$ he United Nations Conference on Environment and Development (UNCED), held in Rio de Janeiro in June 1992, in the context of follow-up arrangements had recommended that the Secretary-General establish a highlevel advisory board consisting of eminent persons knowledgeable about environment and development, including relevant sciences, to be appointed by the SecretaryGeneral in their personal capacity.

Subsequently the UN General Assembly, at its regular session, endorsed the proposals of the Secretary-General regarding the nature, main functions, and general composition, of such a board, and he has now appointed the following 21 individuals to serve on the Board:

Bernard Chidzero (of Zimbabwe), Jacques Cousteau (of France), Birgitta Dahl (of Sweden), Qu Geping (of China), Martin W. Holdgate (of the United Kingdom), Saburo Kawai (of Japan), Tommy Koh (of Singapore), Valentin A. Koptyug (of the Russian Federation), Bola Kuforiji-Olubi (of Nigeria), Rita Levi Montalcini (of Italy), Celso Lafer (of Brazil), Maria de los Angeles Moreno (of Mexico), Laura Novoa (of Chile), Justice R.S. Pathak (of India), Emil Salim (of Indonesia), Marie Angelique Savane (of Senegal), Klaus Schwab (of Germany), Stefan Schmidheiny (of Switzerland), Adeles Simmons (of the United States), Maurice F. Strong (of Canada), and Mostafa K. Tolba (of Egypt).

The Board will serve as a high-level source of advice for the Secretary-General in formulating policy proposals, elaborating innovative approaches and courses for action, and identifying emerging issues to be brought to the attention of relevant intergovernmental bodies - particularly the Commission on Sustainable Development and the Economic and Social Council, including the high-level segments of those bodies, as well as the Administrative Committee on Coordination (ACC).

In more specific terms, the Board is to have the following functions:

(a) To provide high-level advice, proposals, and recommendations, on issues and themes to be addressed by the Commission on Sustainable Development and the Commission's high-level meetings;

(b) To bring to the attention of the Secretary-General and, through him, to that of the relevant intergovernmental bodies, emerging problems related to 'sustainable development' and possible ways and means for resolving them;

(c) To provide the UN Secretary-General and, through him, the ACC, with its views on the expectations and concerns of major constituencies and groups on sustainable development issues and on the contribution of the United Nations system in addressing those issues;

(d) To contribute to the building of partnerships between the United Nations and the scientific, business, and academic, communities and major non-governmental groups; and

(e) To promote knowledge and understanding of, and mobilize support for, United Nations activities in the area of environment and development throughout the constituencies and groups represented by its members.

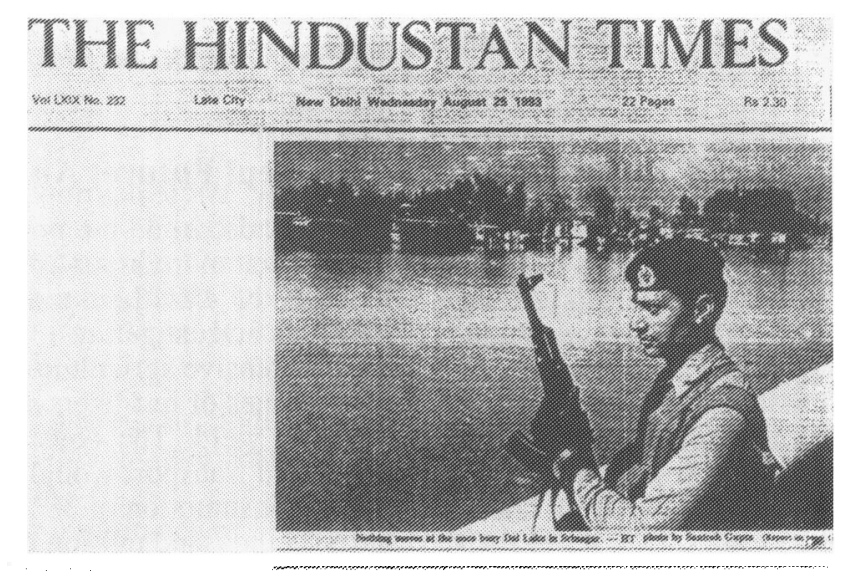

Press photo with the caption 'Nothing moves at the once busy Dal Lake in Srinagar', as an indication of why Dr Khan declined to return to the Lake for further studies as recommended by a specialist referee, whereupon we requested reduction of his paper to the short communication published on pages $352-6$ of this issue. 